Magna Scientia Advanced Research and Reviews

eISSN: 2582-9394

Cross Ref DOI: $10.30574 / \mathrm{msarr}$

Journal homepage: https://magnascientiapub.com/journals/msarr/

(REVIEW ARTICLE)

\title{
Update on aesthetic coronoradicular reconstructions of posterior teeth
}

\author{
Sihem Hajjaji *, Hayet Hajjemi and Abdelatif Boughzela \\ Department of dentistry, Farhat Hached university hospital, sousse/ Tunisia.
}

Magna Scientia Advanced Research and Reviews, 2021, 03(02), 040-046

Publication history: Received on 10 October 2021; revised on 16 November 2021; accepted on 18 November 2021

Article DOI: https://doi.org/10.30574/msarr.2021.3.2.0078

\begin{abstract}
The restoration of teeth treated endodontically and having undergone significant loss of substance remains a challenge for dental surgeons. It represents one of the most frequent clinical sequences of general practice on a daily basis.

This act is so common and so repetitive that the practitioner often performs it automatically, almost reflexively, applying the same mode of restoration to most clinical situations.

Metal coronoradicular restorations (RCR) have long been considered the standard for restoring depulpated posterior teeth, as this type of restorations offer increased mechanical resistance to the occlusal stresses to which posterior teeth are subjected.

The advent of adhesive dentistry has revolutionized the restoration of depulpated posterior teeth. It has become possible today to combine aesthetics, mechanical resistance and biocompatibility thanks to the fiber-based coronoradicular restoration of the posterior sector.
\end{abstract}

In this article, we will detail the clinical protocol for an esthetic restoration of two premolars treated endodontically and severely damaged.

Keywords: Fiber posts; Bonding; Aesthetics; Coronoradicular reconstruction

\section{Introduction}

The reconstruction of depulpated teeth is a real challenge in daily practice. Indeed, the principles of tissue economy, modern techniques of endodontic retreatment and bonding allow us to push ever further the limits of conservation of the depulpated tooth [15].

Performing a pre-prosthetic coronary radicular reconstruction is an essential act of prosthetic restoration. Indeed, we give this type of restoration a difficult role in restoring the loss of substance, in maintaining the canal seal, in mechanically reliable and stable connection between the dental organ and the prosthetic superstructure [1, 11].

Today, faced with increasingly high aesthetic requirements, the dental surgeon has to review his clinical method. It has become essential to complete the existing therapeutic range with adhesive reconstitutions, in order to ensure good biomechanical conditions and to offer the patient the desirable aesthetic result [3].

\footnotetext{
${ }^{*}$ Corresponding author: Sihem Hajjaji

Department of dentistry, Farhat Hached university hospital, sousse/ Tunisia.

Copyright $(2021$ Author(s) retain the copyright of this article. This article is published under the terms of the Creative Commons Attribution Liscense 4.0.
} 
Coronoradicular restorations bonded with fiber posts are now recognized as an excellent alternative to coronoradicular restorations using cast metal posts. Their success is directly linked to the advantages of so-called "adhesive" dentistry that is biologically compatible, less mutilating and which allows rehabilitations of high aesthetic quality [20].

\section{Overview of coronoradicular reconstitutions of the posterior teeth}

\subsection{Fiber posts}

Fiber reinforced composite posts (fig. 1), or fiber posts, are an alternative to traditional cast or prefabricated metal posts. They were introduced in the 1990s and became popular with the advent of adhesive techniques, which changed the way of restoring endodontically treated teeth [10]. Compared to cast posts, fiber posts have mechanical properties similar to those of dentin and can distribute stresses to the root more evenly, thereby reducing the risk of root fracture (Fig. 2). In addition, fiber posts are aesthetic, practical and removable in the context of root canal retreatment. However, they can also increase the stress concentration in the cervical dentin as well as at the edge of the restoration $[18,6]$.

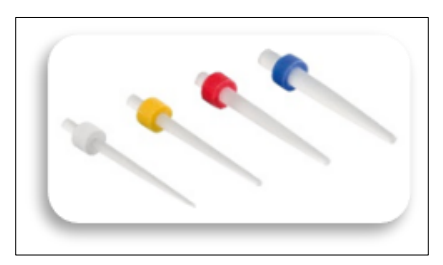

Figure 1 Different shapes of Quartz fiber posts [16]

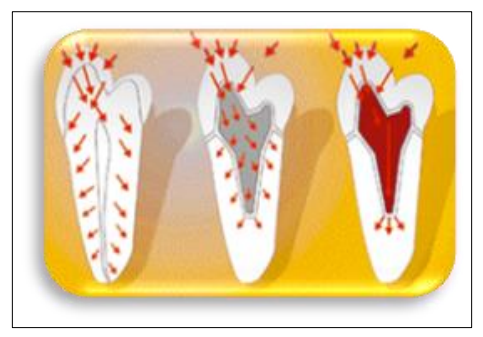

Figure 2 Comparison of the stress distribution between a natural tooth (a), a fiber-reinforced CPR (b) and a metallic inlay core (c) [7]

\subsection{Strapping}

Generally, strapping is the most important clinical factor for the mechanical resistance of the endodontically treated tooth. The presence of adequate cerclage decreases the impact of coronoradicular restoration, bonding agents and the final restoration on the durability of endodontically restored teeth. Teeth prepared with cerclage tend to fracture more favorably if they fail. The proposed effective strapping height ranges from $1.5 \mathrm{~mm}$ to $2 \mathrm{~mm}[13,14]$. Resistance appears to increase considerably with increased cerclage height, and a better prognosis is to be expected if the cerclage is uniform (Fig. 3).

However, according to some authors, non-uniform cerclage still considerably increases the fracture resistance of the restored tooth.

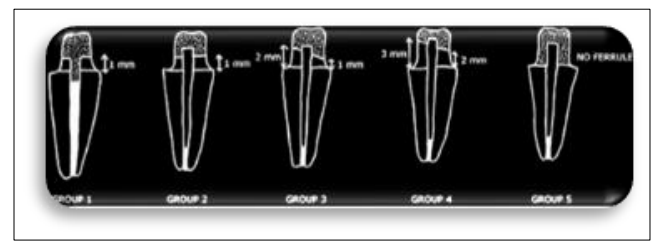

Figure 3 Different strapping configurations [4] 


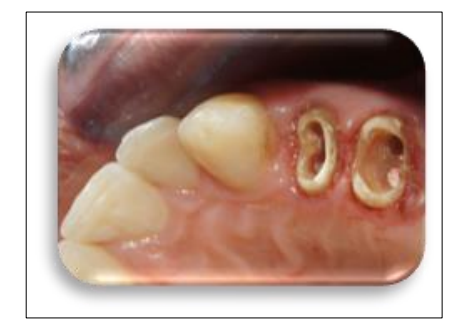

Figure 4 Initial view of 24 and 25

\section{Clinical procedures}

\subsection{Presentation of the case}

A 40-year-old patient consulted for the replacement of the missing 26. Clinical examination revealed satisfactory hygiene, subtotal but supragingival decay of all the walls at the level of 24 and 25 (fig. 4).

On radiological examination, the periodontal and endodontic environment were favorable for coronoradicular restoration. Our prosthetic decision focused on a ceramic-metal bridge replacing the 26 and having 24,25 and 27 as supporting teeth.

In this article, we will focus on the reconstruction of 24 and 25 for which we have opted for fiber-bonded coronoradicular restoration.

\subsection{Root canal preparation}

The coronal portion having been cleared of altered tissues and obturation residues, the passage of a series of Largo drills of increasing diameter eliminates most of the endodontic filling material, and begins the canal preparation which will receive the post. (fig. 5). The length of the root canal preparation must be adapted to the anatomy of the tooth in question, while taking into account the additional retention provided by the bonding of the reconstruction, making it possible to reduce its depth to limits much less than the root two-thirds recommended for metal posts [8].

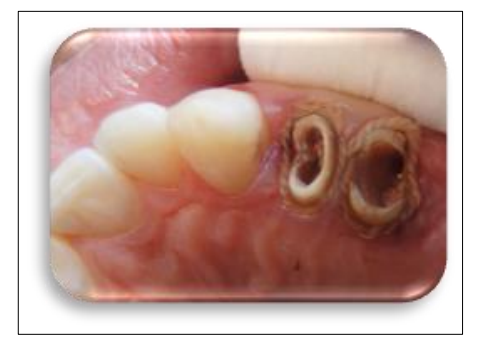

Figure 5 Root canal preparation to receive the posts

\subsection{Adhesive procedures and post bonding}

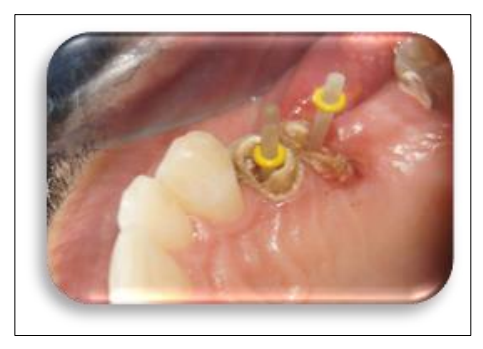

Figure 6 Try-in of the posts 
The try-in of fiber posts in root canal preparations initiated this bonding step (fig. 6). Once adapted, these posts were coated with an adhesive and then light-cured (fig. 7.a, b). The same procedure was applied to the post seats (fig. 8.a, b). We have selected a dual adhesive system which has a specific micro-applicator to obtain a quality hybrid layer [5].
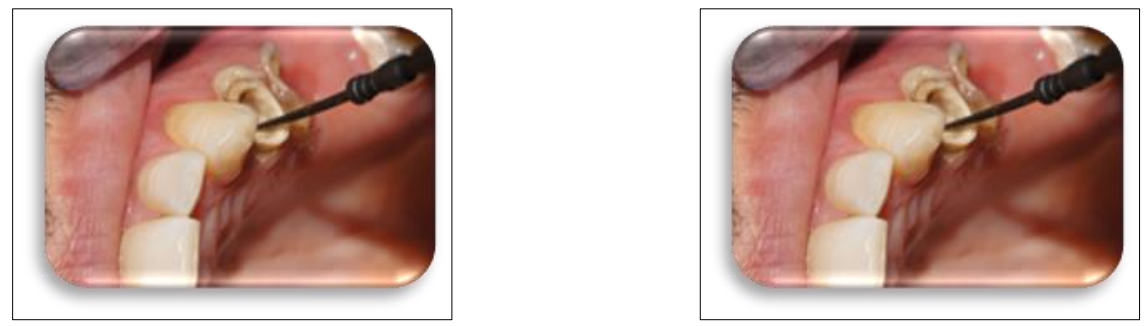

Figure 7 a: application of the adhesive in the canal / b: light-curing
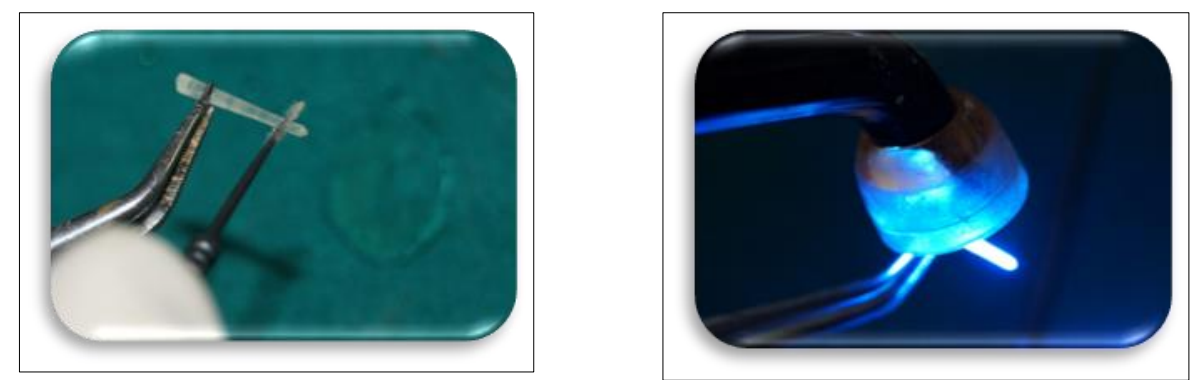

Figure 8 a: application of the adhesive to the post / b: light-curing

The application of the dual resin at the root canal level, the placement of the post and its photopolymerization (fig. 9.a, b, c) completed this bonding step. The resin must fill the spaces and coat the post in order to absorb and distribute, thanks to a modulus of elasticity close to that of dentin, the forces applied to it. Finally, thanks to its bonding capacity with the adhesive, it contributes to the cohesion of the whole [9]. It was injected into the housing to fill it completely, without the risk of leaving empty spaces.
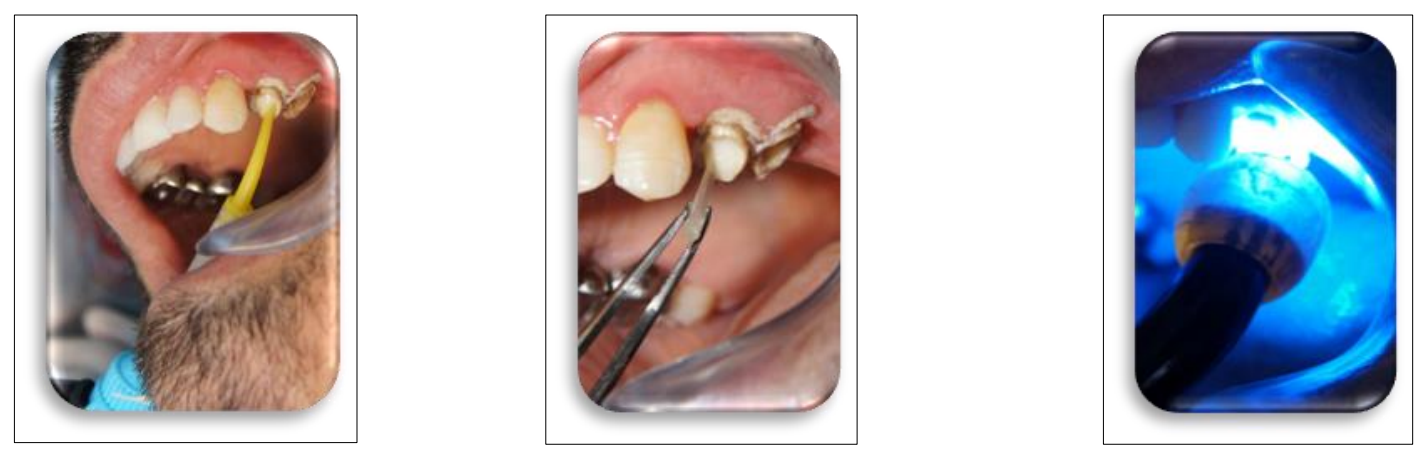

Figure 9 a: Application of the Dual resin, b: placement of the post, c: light-curing

Coronary reconstitution (fig. 10) is carried out at the same time with the same material in order to obtain a homogeneous whole and to avoid the multiplication of interfaces [12] (between the coronal reconstitution composite and the root composite) at the origin of weakening of the core. all. These stumps were protected by two temporary crowns (fig. 11). 


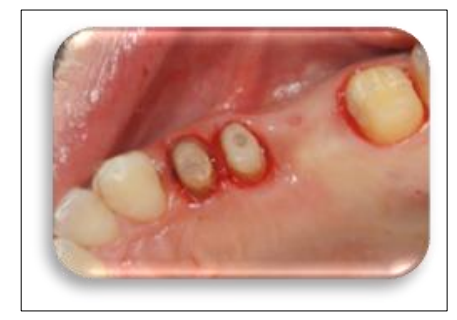

Figure 10 Coronary restoration

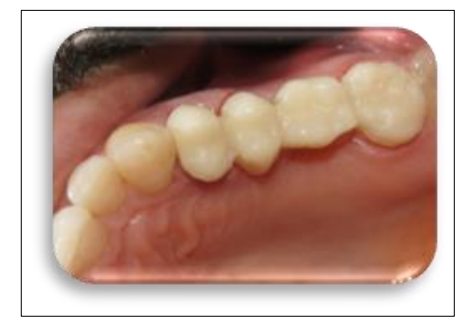

Figure 11 Cementing of the temporary prosthesis

\subsection{Prosthetic realization}

An impression of the dental preparations and the entire arch was made using addition silicones (Fig. 12.a, b). This impression allowed a faithful transfer of the clinical situation to the prosthesis laboratory.
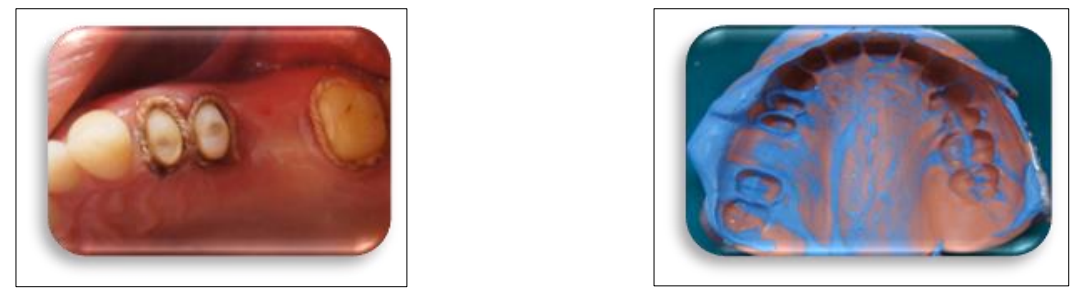

Figure 12 a: gingival eviction / b: Global impression

Upon receipt of the metal framework, a try-in was carried out in the mouth (fig. 13) in order to check the adaptation, retention and stability of the bridge, as well as the space left for the veneering ceramic. When this was fitted, a new tryin was carried out (fig. 14) in order to check the points of contact, the occlusion and the aesthetic integration in the mouth.

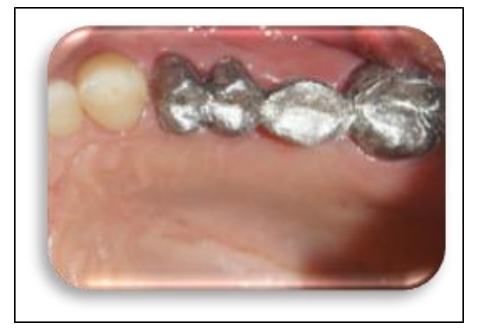

Figure 13 Testing the metal frame 


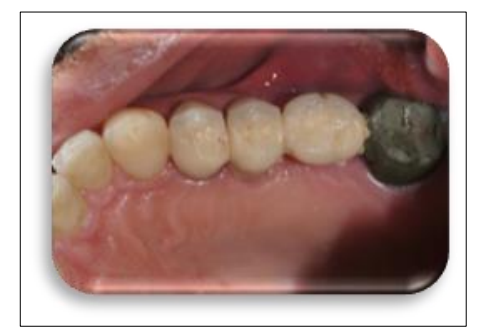

Figure 14 Installation of the veneer ceramic

The final aesthetic rendering was judged after glazing the ceramic. The result was satisfactory in the eyes of the patient and the entire healthcare team (Fig. 15).

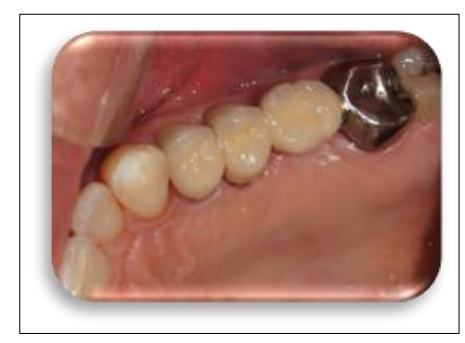

Figure 15 Final aesthetic result

\section{Conclusion}

Although the performance of coronoradicular restoration is a daily and repetitive act, it can however, by the presence of the root posts, constitute a real danger for the durability of the tooth. In order to limit the risks, it is imperative to strive for maximum tissue savings, both in terms of coronary preparations and canal housings, in order to maintain thicknesses capable of withstanding excessive occlusal stresses at the posterior level, and to select materials of reconstruction and junction capable of respecting the physiology of the depulpated posterior tooth $[19,17]$.

Bonded coronoradicular restoration now seem to be an excellent alternative to cast metal ones in terms of mechanics, aesthetics and biocompatibility.

However, this alternative requires on the one hand a good mastery of root canal preparation techniques which must offer greater tissue economy, and on the other hand a good mastery of bonding techniques adapted to the material chosen, in order to limit failures by unsealing of the restoration [3].

\section{Compliance with ethical standards}

\section{Disclosure of conflict of interest}

No conflict of interest.

\section{References}

[1] Reeh ES, Messer HH, Douglas WH. Reduction in tooth stiffness as a result of endodontic and restorative procedures. J Endod. 1989; 15(11): 512-6.

[2] Dietschi D, Duc O, Krejci I, Sadan A. Biomechanical considerations for the restoration of endodontically treated teeth: a systematic review of the literature, Part II (Evaluation of fatigue behavior, interfaces, and in vivo studies). Quintessence Int Berl Ger 1985. Feb 2008; 39(2): 117-29. 
[3] Dietschi D, Duc 0, Krejci I, Sadan A. Biomechanical considerations for the restoration of endodontically treated teeth: A systematic review of the literature-Part 1. Composition and micro- and macrostructure alterations. QUINTESSENCE Int. 2007; 38(9): 11.

[4] Juloski J, Radovic I, Goracci C, Vulicevic ZR, Ferrari M. Ferrule Effect: A Literature Review. J Endod. Jan 2012; 38(1): 11-9.

[5] da Silva NR, Raposo LHA, Versluis A, Fernandes-Neto AJ, Soares CJ. The effect of post, core, crown type, and ferrule presence on the biomechanical behavior of endodontically treated bovine anterior teeth. J Prosthet Dent. Nov 2010; 104(5): 306-17.

[6] Segerström S, Astbäck J, Ekstrand KD. A retrospective long term study of teeth restored with prefabricated carbon fiber reinforced epoxy resin posts. Swed Dent J. 2006; 30(1): 1-8.

[7] Akkayan B, Gülmez T. Resistance to fracture of endodontically treated teeth restored with different post systems. J Prosthet Dent. Apr 2002; 87(4): 431-7.

[8] Schwartz RS, Robbins JW. Post placement and restoration of endodontically treated teeth: a literature review. J Endod. May 2004; 30(5): 289-301.

[9] Qualtrough AJE, Mannocci F. Tooth-colored post systems: a review. Oper Dent. Feb 2003; 28(1): 86-91.

[10] Schmitter M, Rammelsberg P, Lenz J, Scheuber S, Schweizerhof K, Rues S. Teeth restored using fiber-reinforced posts: in vitro fracture tests and finite element analysis. Acta Biomater. Sep 2010; 6(9): 3747-54.

[11] Soares CJ, Rodrigues M de P, Faria-E-Silva AL, Santos-Filho PCF, Veríssimo C, Kim HC, et al. How biomechanics can affect the endodontic treated teeth and their restorative procedures? Braz Oral Res. 18 Oct 2018; 32(suppl 1): e76.

[12] Pereira JR, de Ornelas F, Conti PCR. Effect of a crown ferrule on the fracture resistance of endodontically treated teeth restored with prefabricated posts. J Prosthet Dent. 2006; 95(1): 5.

[13] Naumann M, Schmitter M, Frankenberger R, Krastl G. "Ferrule Comes First. Post Is Second!" Fake News and Alternative Facts? A Systematic Review. J Endod. Feb 2018; 44(2): 212-9.

[14] Stankiewicz NR, Wilson PR. The ferrule effect: a literature review. Int Endod J. Jul 2002; 35(7): $575-81$.

[15] Ferrari M, Cagidiaco MC, Grandini S, De Sanctis M, Goracci C. Post Placement Affects Survival of Endodontically Treated Premolars. J Dent Res. Aug 2007; 86(8): 729-34.

[16] Cagidiaco MC, García-Godoy F, Vichi A, Grandini S, Goracci C, Ferrari M. Placement of fiber prefabricated or custom made posts affects the 3-year survival of endodontically treated premolars. Am J Dent. Jun 2008; 21(3): 179-84.

[17] Ferrari M, Vichi A, Fadda GM, Cagidiaco MC, Tay FR, Breschi L, et al. A Randomized Controlled Trial of Endodontically Treated and Restored Premolars. J Dent Res. Jul 2012; 91(7_suppl): S72-8.

[18] Salameh Z, Ounsi HF, Aboushelib MN, Sadig W, Ferrari M. Fracture resistance and failure patterns of endodontically treated mandibular molars with and without glass fiber post in combination with a zirconiaceramic crown. J Dent. Jul 2008; 36(7): 513-9.

[19] Scotti N, Coero Borga FA, Alovisi M, Rota R, Pasqualini D, Berutti E. Is fracture resistance of endodontically treated mandibular molars restored with indirect onlay composite restorations influenced by fibre post insertion? J Dent. Oct 2012; 40(10): 814-20.

[20] Magne P, Goldberg J, Edelhoff D, Güth J-F. Composite Resin Core Buildups With and Without Post for the Restoration of Endodontically Treated Molars without Ferrule. Oper Dent. Feb 2016; 41(1): 64-75. 